\title{
PROPOSTA EDUCATIVA UTILIZANDO O JOGO RPG MAKER: ESTRATÉGIA DE CONSCIENTIZAÇÃO E DE APRENDIZAGEM DA QUÍMICA AMBIENTAL
}

\author{
T. V. PAULA ${ }^{1}$, E. V. P. SOUZA ${ }^{2}$, T. G. N. SILVA ${ }^{1}$, D. M. SILVA ${ }^{3}$ e M. E. N. P. RIBEIRO ${ }^{1,3^{*}}$ \\ ${ }^{1}$ Universidade Federal do Ceará \\ ${ }^{2}$ Instituto Federal de Educação, Ciência e Tecnologia do Ceará \\ ${ }^{3}$ Instituto Federal de Educação, Ciência e Tecnologia do Rio Grande do Norte \\ elenir.ribeiro@ufc.br ${ }^{*}$
}

Artigo submetido em novembro/2013 e aceito em junho/2015

DOI: $10.15628 /$ holos.2015.1844

\section{RESUMO}

Este trabalho refere-se à utilização do RPG Maker (software educativo) como objeto de aprendizagem (OA) para conscientização e contextualização do ensino de Química, no âmbito do Ensino Médio. A relação entre a Educação Ambiental e o ensino de Química possibilita aos educandos observar as transformações que ocorrem no ambiente melhorando, por conseguinte, sua compreensão dos conteúdos. Visto que é o professor que tem a função de escolher a metodologia que viabilize a reflexão e uma compreensão crítica sobre a realidade em que o aluno está inserido, propõe-se que uma das formas viáveis de trabalhar a Educação Ambiental no ensino de Química é contextualizar os assuntos utilizando um $O A$, como o software educativo baseado no RPG Maker. Conforme foi visualizado neste trabalho, o uso do OA tornou a aula mais interessante, contextualizada e facilitou a aprendizagem do assunto relacionado à Química Ambiental.

PALAVRAS-CHAVE: Educação Ambiental, Química, Objeto de Aprendizagem, Software Educativo, RPG Maker.

\section{EDUCACIONAL PROPOSAL USING GAME RPG MAKER: STRATEGY OF AWARENESS AND LEARNING OF ENVIRONMENTAL CHEMISTRY}

\begin{abstract}
This work refers to the use of RPG Maker (educational software ) as a learning object (OA) for awareness and contextualization of the teaching of Chemistry in Secondary School. The relationship between environmental education and the Chemistry teaching enables the students to observe the changes that occurr in the environment improving therefore their understanding of the content. Since the teacher has the function to choose the methodology that enables
\end{abstract}

reflection and a critical understanding of the reality in which the student is inserted, it is proposed that one of the viable ways of working environmental education in chemistry teaching is to contextualize subjects using an LO, like the educational software based on the RPG Maker. As it was visualized in this work, the use of the LO made the class more interesting and contextualized, facilitating the learning related to environmental education issue.

KEYWORDS: Environmental Education, Chemistry, Learning Object, Educational Software, RPG Maker. 


\section{INTRODUÇÃO}

A questão envolvendo o tema ambiental tornou-se recorrente, visto que a poluição evoluiu muito ao longo dos anos com o desenvolvimento do setor industrial, gerando até problemas de saúde pública.

A definição da educação ambiental é dada no artigo 1ำ da Lei no 9.795/99 como:

os processos por meio dos quais o indivíduo e a coletividade constroem valores sociais, conhecimentos, habilidades, atitudes e competências voltadas para a conservação do meio ambiente, bem de uso comum do povo, essencial à sadia qualidade de vida e sua sustentabilidade (BRASIL, Lei $n^{\circ}$ 9.795/99).

Embora apresente um enfoque de conservação, essa definição deixa claro o local do ser humano como responsável individual (na esfera privada) e coletivo (na esfera pública) pela sustentabilidade. Desta forma, a preservação é responsabilidade de todos e não somente de alguns indivíduos. Uma vez que a biodiversidade do planeta é o assunto em destaque, surge a escola como a principal formadora de cidadãos brasileiros conscientes que venham agir de modo responsável na sociedade em que estão inseridos.

De forma a reforçar e qualificar o direito de todos à Educação Ambiental, foi aprovada a Lei que estabelece a Política Nacional de Educação Ambiental (PNEA) como: "um componente essencial e permanente da educação nacional" conforme rege seu 20 (BRASIL, Lei no 9.795/99).

Segundo Carvalho (2001), é preciso uma "educação ambiental cidadã que permita ampla participação nos processos coletivos de tomada de decisões, buscando a afirmação de uma sociedade de direitos, ambientalmente justa." (Carvalho, 2001, p. 58).

Diante deste pensamento, Ferreira (2010) afirma que:

pode-se introduzir a Educação Ambiental em aulas de Química com abordagem socioambiental. A intenção é que sob esse novo olhar, o professor de Química possa refletir sobre sua prática pedagógica e passe a buscar a ligação dos conteúdos químicos aos temas ambientais. (Ferreira, 2010, p. 86, 87).

A relação entre a Educação Ambiental e o Ensino da Química possibilita ao educando observar as transformações que ocorrem no ambiente, com isso melhorando sua compreensão dos conteúdos. Visto que o professor tem a função de desenvolver uma metodologia que viabilize a reflexão e uma compreensão crítica sobre a realidade da vida, percebe-se que uma das formas viáveis de trabalhar a Educação Ambiental no Ensino de Química é contextualizar os assuntos utilizando um objeto de aprendizagem (OA), como um software educativo.

A utilização de software educativo na área da Química e do Meio Ambiente, para desenvolver conteúdos previstos no plano de ensino, vem proporcionar oportunidades para o educando refletir sobre suas ações com relação ao ambiente, permitindo a socialização de conhecimentos, assim como a valorização de práticas ambientalmente corretas.

Nessa perspectiva, o software é um objeto de aprendizagem e por isso é definido como software educativo que caracteriza-se "como sendo um sistema computacional e interativo, intencionalmente concebido para facilitar a aprendizagem de conceitos específicos, por exemplo, 
conceitos matemáticos ou científicos" (Gomes e Padovani (2005),), ou seja, instrumento para a aprendizagem de algo. Pode-se ainda afirmar que os softwares educacionais são os softwares pensados, programados e implementados com objetivos educativos - dentro e fora da esfera escolar.

Para esclarecer o que é um objeto de aprendizagem, podemos afirmar que "um objeto de aprendizagem pode ser conceituado como sendo todo objeto que é utilizado como meio de ensino/aprendizagem" (Gutierrez, 2004, p.6). Neste contexto, o RPG, que é a sigla para Role Playing Game, é um objeto de aprendizagem. O RPG, também conhecido como "jogo de interpretação de papéis", é um jogo no qual os participantes criam seus personagens por meio da atribuição de características físicas, mentais, sociais, etc. Por meio deste recurso torna-se possível criar um ambiente de simulações, incentivando o desenvolvimento de habilidades procedimentais e atitudinais nos alunos, tais como o estabelecimento de estratégias, curiosidade, motivação, integração, desenvoltura para trabalhar em grupo, autonomia, liderança. Outro aspecto importante a ser mencionado se constitui no fato de que o RPG pode ser adaptado a qualquer área do conhecimento e conteúdo didático, ambiente ou público (Nunes, 2004).

Os RPGs Makers são ferramentas que permitem ao usuário a criação de seus próprios jogos de RPG computadorizados. Vale ressaltar que a maioria destes makers permite a criação de jogos com as características dos jogos clássicos de RPG, com um único jogador e criação de tramas limitadas e extremamente lineares. Mas apresenta como ponto positivo, o fato de permitir que o usuário transforme suas ideias em um jogo computadorizado (Bittencourt e Girrafa, 2003). Conforme destaca Nascimento Jr. e Pietrocola (2005), a utilização do RPG deve ser vista como "uma ferramenta para ensinar ao aluno a construir seu acesso à visão de mundo que desejamos que desenvolva" (Nascimento Jr. e Pietrocola, 2005, p.07).

Um fato importante que devemos citar para a escolha deste software é a possibilidade do jogo criado em formato eletrônico não ter necessariamente a presença de um "mestre", já que o próprio jogo simula o papel desse mestre, sendo estipulados limites para a ação do jogador. A praticidade do RPG Maker facilita a sua utilização para a construção de Jogos Educacionais, já que não são necessários conhecimentos avançados de informática para sua construção.

No presente trabalho foi criado um jogo, baseado no software RPG Maker, no qual os assuntos abordados foram questões relacionadas aos impactos ambientais.

Foram abordados os seguintes assuntos no jogo:

1) Chuva ácida;

2) Identificação de substâncias, suas propriedades químicas (vantagens e desvantagens);

3) Agrotóxicos;

4) Efeito dos metais pesados;

5) Efeito estufa.

Este trabalho tem como objetivo propor um objeto de aprendizagem baseado no RPG Maker como software educativo para conscientização e contextualização do ensino de Química Ambiental, nas aulas de Química no âmbito do Ensino Médio.

A Figura 1 apresenta a tela principal do RPG Maker e a Figura 2 apresenta o jogo de RPG Maker criado na área de Química Ambiental para aplicação deste estudo. 


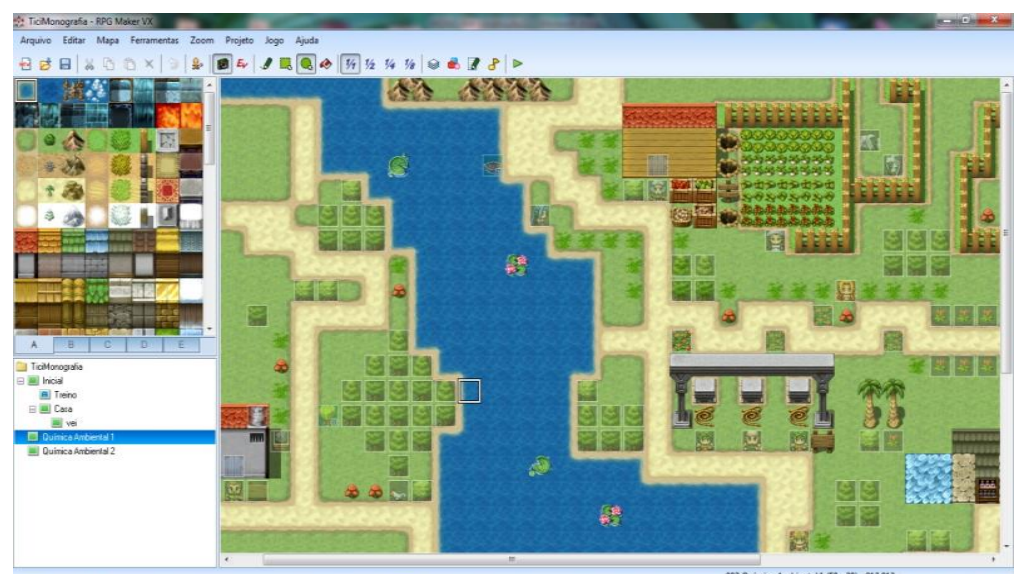

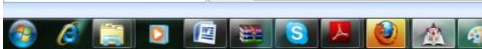

Figura 1: Tela principal - Construção do mapa do RPG.

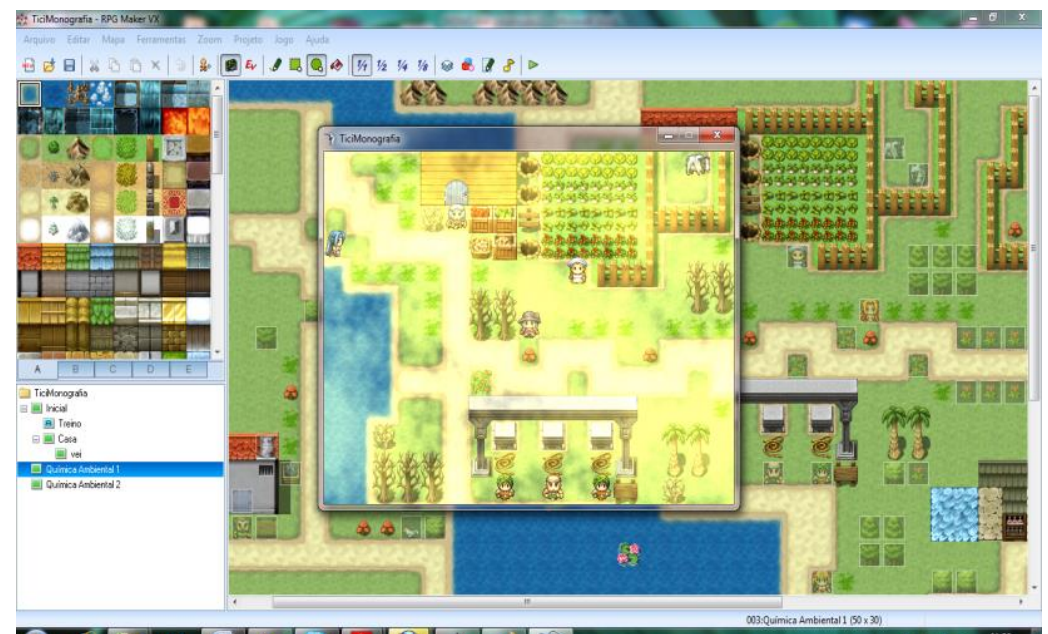

Figura 2: Jogo de Química Ambiental.

\section{METODOLOGIA}

Devido à grande problemática existente no que diz respeito à Educação Ambiental e à conscientização da sociedade para esta problemática, e considerando a escola como um espaço de aprendizagem e reprodutora de cidadãos conscientes de suas responsabilidades, optou-se por fazer um estudo de caso sobre o assunto.

Foi construído um jogo utilizando o software RPG Maker VX, envolvendo questões da Química Ambiental. 0 jogo confeccionado foi aplicado em 2 turmas de $3^{\circ}$ Série do Ensino Médio, no ano de 2011, com um total de 100 alunos, na Escola de Ensino Médio Liceu Vila Velha, FortalezaCE- Brasil, para testar sua viabilidade como recurso didático no ensino e aprendizagem. Após a demonstração do jogo para os alunos, foi aplicado um questionário para avaliar o nível de entendimento do jogo pelos participantes, bem como o assunto abordado. Avaliou-se também se eles consideraram o jogo como um bom recurso que contribui na sua aprendizagem; se foi possível relacionar o conteúdo teórico do jogo com o seu cotidiano, entre outros questionamentos (Quadro 1). A análise do questionário deu-se de acordo com Análise de Conteúdo proposta por Bardin. 
Quadro 1: Questionário aplicado aos alunos.

Questionário

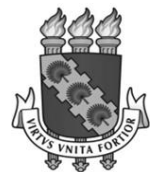

Universidade Federal do Ceará

Centro de Ciências

Departamento de Química Orgânica e Inorgânica

Curso de Licenciatura em Química

ESCOLA:

SEXO: ( )Feminino (1)Masculino - IDADE

anos - SÉRIE: ano - TURMA:

1- Você entendeu o objetivo do jogo?
a) $\operatorname{Sim}()$
b) Não ( )

2-O que você achou do software educacional aplicado ao ensino da Química Ambiental?
a) Ruim ( )
b) Bom ( ) c) Ótimo ( )
d) Excelente ( )

3-Você acha que a utilização de jogos contribui para a fixação do conteúdo para sua aprendizagem?
a) $\operatorname{Sim}()$
b) Não ( )

4-Na sua opinião a aula se torna mais interessante com a utilização desses recursos educacionais?
a) $\operatorname{Sim}()$
b) Não ( )

5-Você conseguiu relacionar o conteúdo teórico do jogo com o seu cotidiano?
a) $\operatorname{Sim}()$
b) Não ( )

6-Se as aulas teóricas de Química relacionassem sempre o contéudo visto em sala com o cotidiano, facilitaria mais sua compreensão e aprendizagem do conteúdo dado?
a) $\operatorname{Sim}()$
b) Não ( )

\subsection{Descrição do Jogo - os impactos ambientais e a Química}

Foi construído um jogo abordando assuntos sobre impactos ambientais que são ocasionados devido ao uso de produtos químicos.

Ele simula uma cidade virtual, onde a poluição do meio ambiente está muito elevada. $\mathrm{O}$ aspecto visual é primordial neste jogo. Este apresenta uma cidade bastante poluída e pode-se perceber isto através dos aspectos visuais da cidade. Esta inicialmente encontra-se totalmente poluída com uma fumaça bastante densa, demonstrando a poluição do ar, e apresenta também a vegetação praticamente toda seca, demonstrando os prejuízos causados pela poluição.

O objetivo deste jogo é trabalhar a Química relacionando-a com o meio ambiente, criando situações problemas para que os alunos, de uma maneira lúdica, identifiquem vários problemas ambientais desta cidade que são ocasionadas por atividades humanas em indústrias, por meios de transportes, uso de agrotóxicos, pela queima de combustíveis fosseis, entre outros.

À medida que o jogador (no caso, a personagem: maga ambientalista) for acertando as situações problemas, o nível de poluição da cidade diminui até que este atinja o menor nível de poluição, no caso deste jogo o nível igual a dois. Pode-se perceber através do aspecto visual do jogo que à medida que o nível de poluição vai diminuindo o ar da cidade vai se tornando mais limpo e a vegetação fica mais abundante.

Em contrapartida, à medida que o jogador erra as situações problemas o nível de poluição aumenta e a cidade fica mais poluída no aspecto visual. Pode-se perceber isto ao observar que a fumaça fica mais densa e a vegetação fica mais seca. 


\subsection{Demonstração do jogo}

A personagem principal do jogo é uma maga ambientalista que tenta corrigir várias atividades humanas que agravam a poluição ambiental, em sua cidade, pelo uso de produtos químicos (Figura 3).

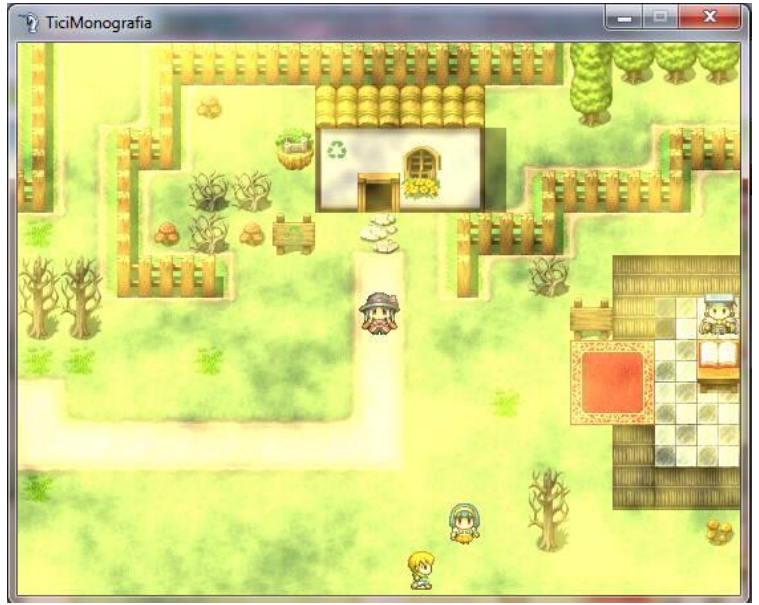

Figura 3: Maga ambientalista no início do jogo.

\subsection{Simulação de acerto}

Os personagens fixos, perto de cada plaquinha de madeira, contêm uma situação problema para o jogador responder. Para acessá-la basta clicar ENTER. Se o jogador acertar, a poluição diminui, caso contrário, a poluição aumenta, conforme mostra a Figura 4.

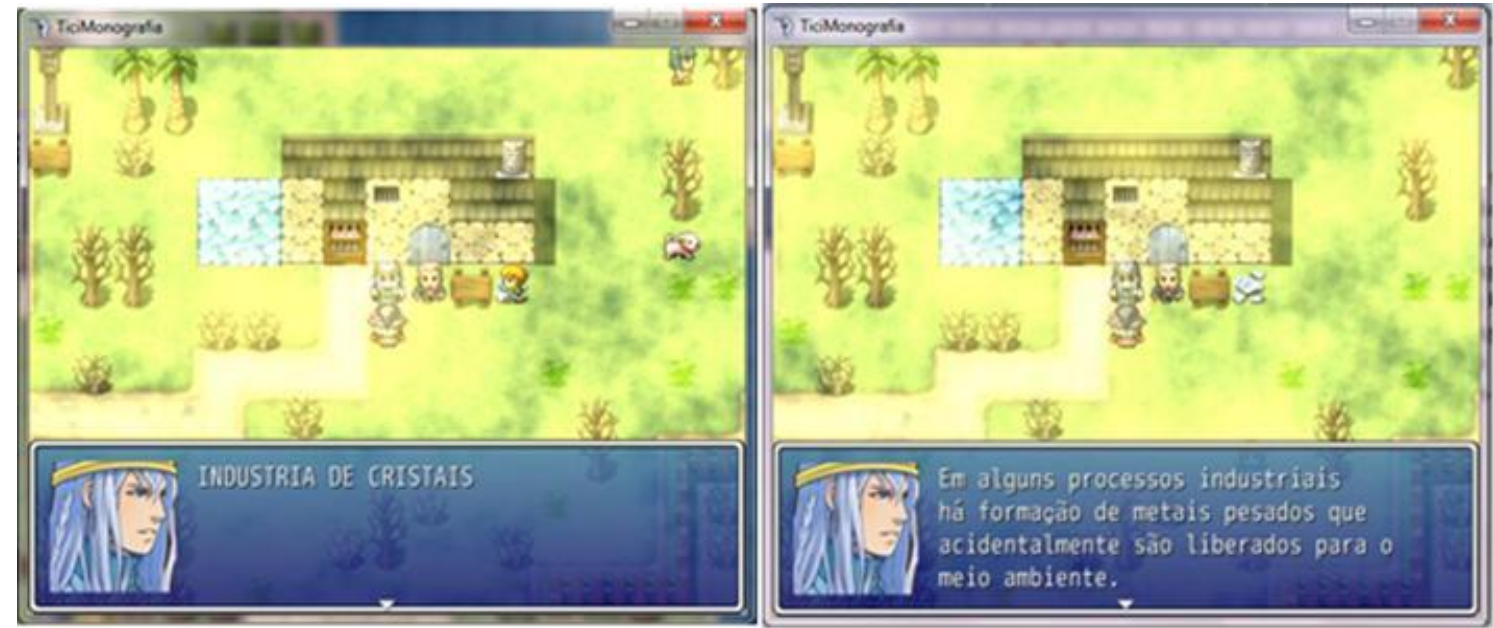

Figura 4: Maga ambientalista vai em busca de resolver a primeira situação problema de sua cidade.

Após a pergunta, deve-se clicar ENTER novamente no personagem e as possíveis respostas aparecerão em uma tela azul abaixo, sendo que apenas uma delas estará correta, conforme mostra a Figura 5. 


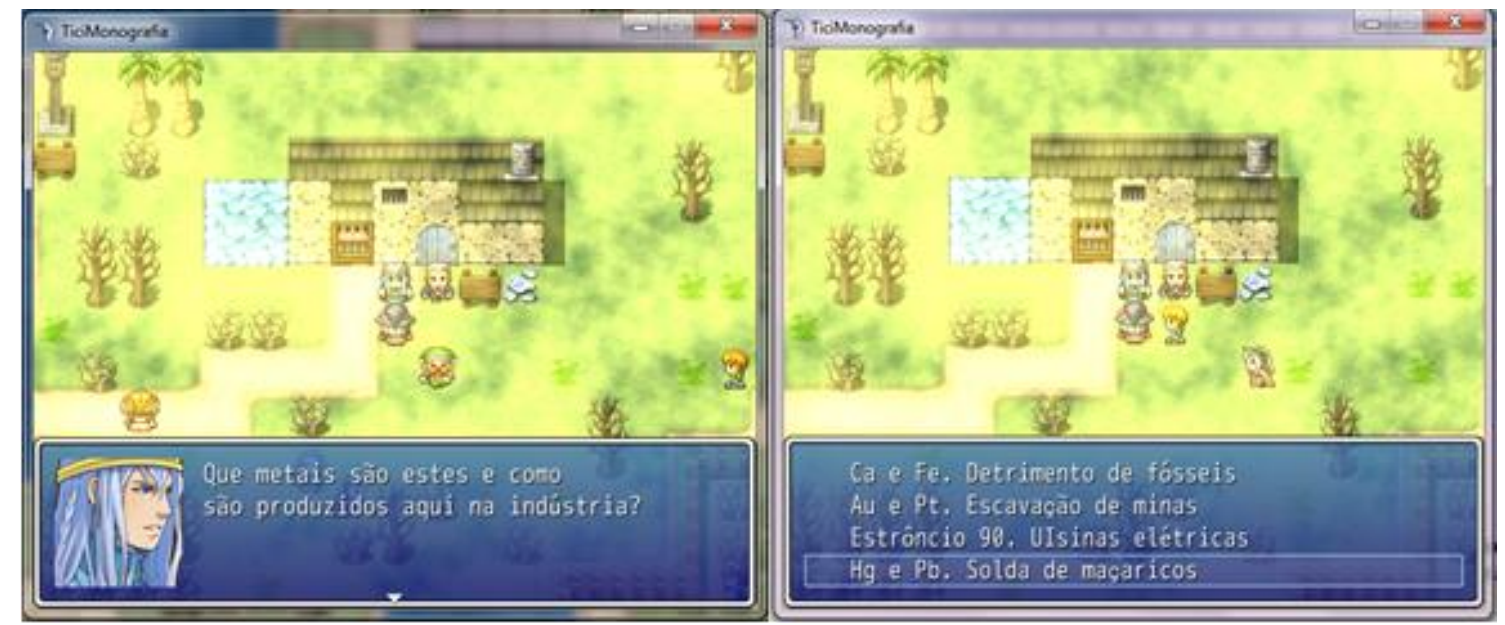

Figura 5: Opções de resposta para situação problema, onde apenas uma é a resposta certa.

Ao clicar na opção correta, o nível de poluição diminui e é possível visualizar essa diminuição através de uma mensagem mostrando a quantidade que diminui, conforme pode ser visto na Figura 6.

Nota-se, pela Figura 6, que após o acerto, a fumaça se torna menos densa e há uma recuperação na vegetação que antes estava seca.

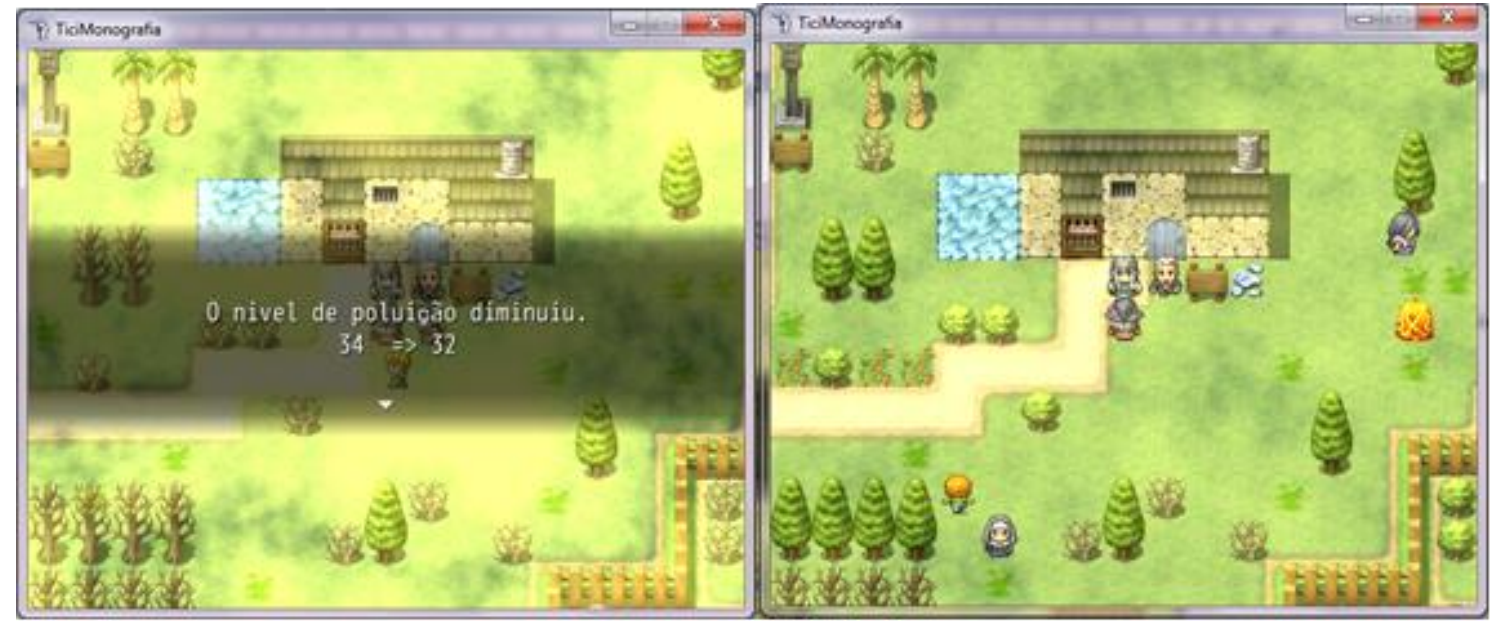

Figura 6: $\mathrm{O}$ acerto do problema em questão diminui a poluição. Ocorre nítida mudança no aspecto das árvores do quadro da esquerda para direita.

\subsection{Simulação de erro}

Outras situações problemas são dadas ao jogador. Procede-se da mesma maneira como foi explicado na situação anterior (Figuras 4 e 5). Clicando com o ENTER no personagem fixo ele Ihe dará uma situação problema conforme é mostrado na Figura 7. 

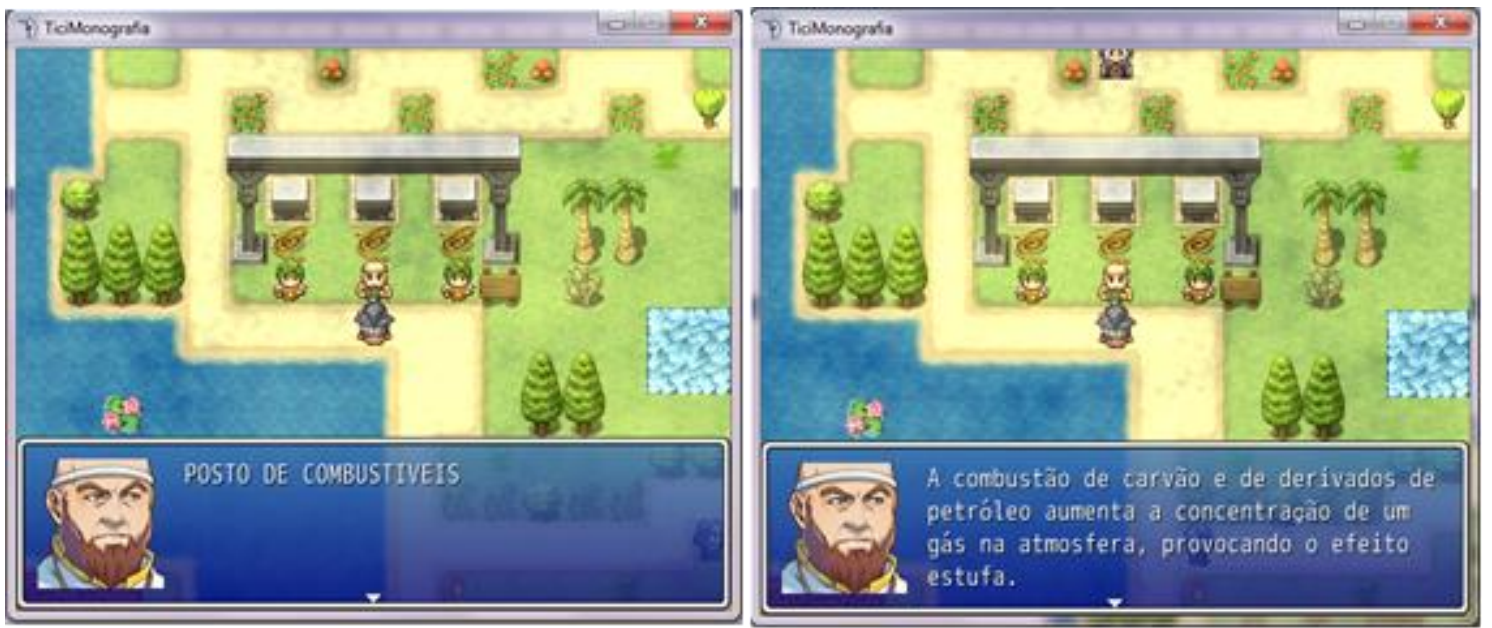

Figura 7: Situação problema dada ao jogador no posto de gasolina.

Após a pergunta feita são dadas novamente as opções de resposta na tela que surge logo abaixo da tela, conforme pode ser visto na Figura 8.
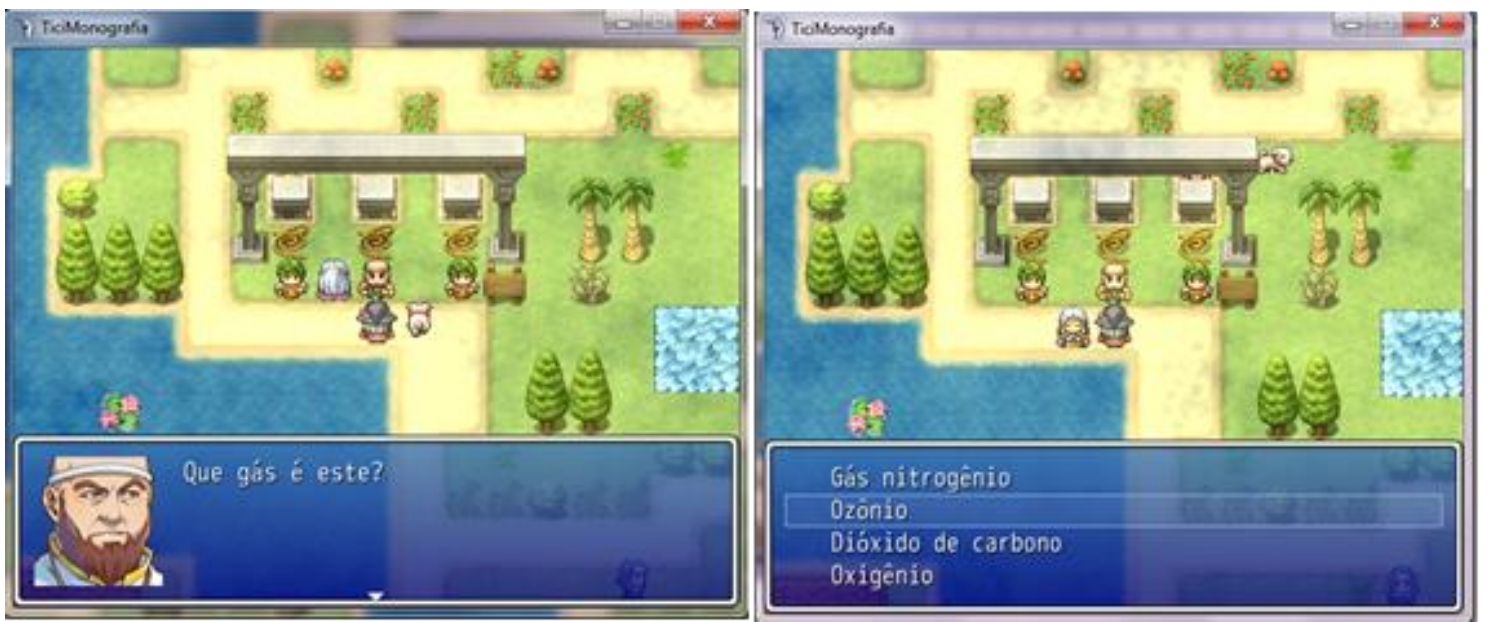

Figura 8: Situação problema no posto de combustível.

Ao marcar a incorreta o nível de poluição aumenta. Pode-se visualizar isso na tela do jogo, como mostrado na Figura 9.
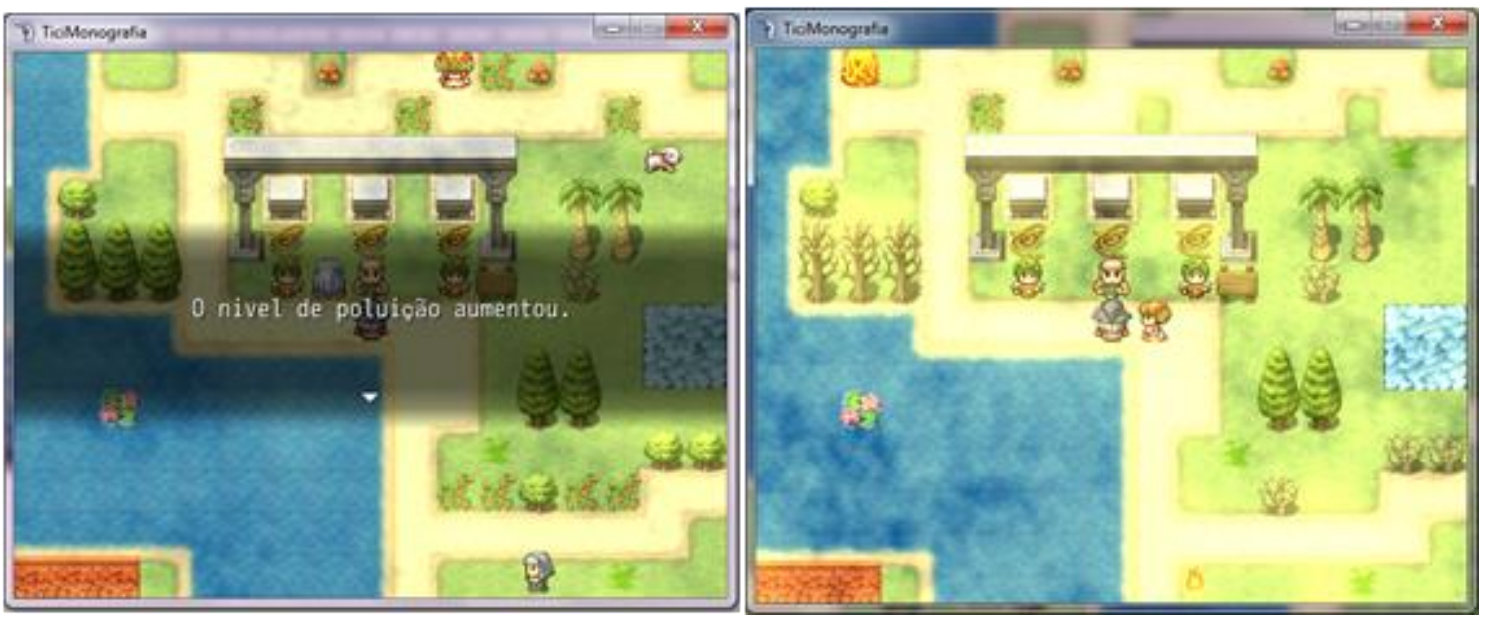

Figura 9: Aumento do nível de poluição devido o erro da resposta. 
Por fim, o jogo termina quando todas as situações problemas dos personagens fixos são respondidas corretamente. No final, o jogador é parabenizado por ter contribuído com a "despoluição ambiental".
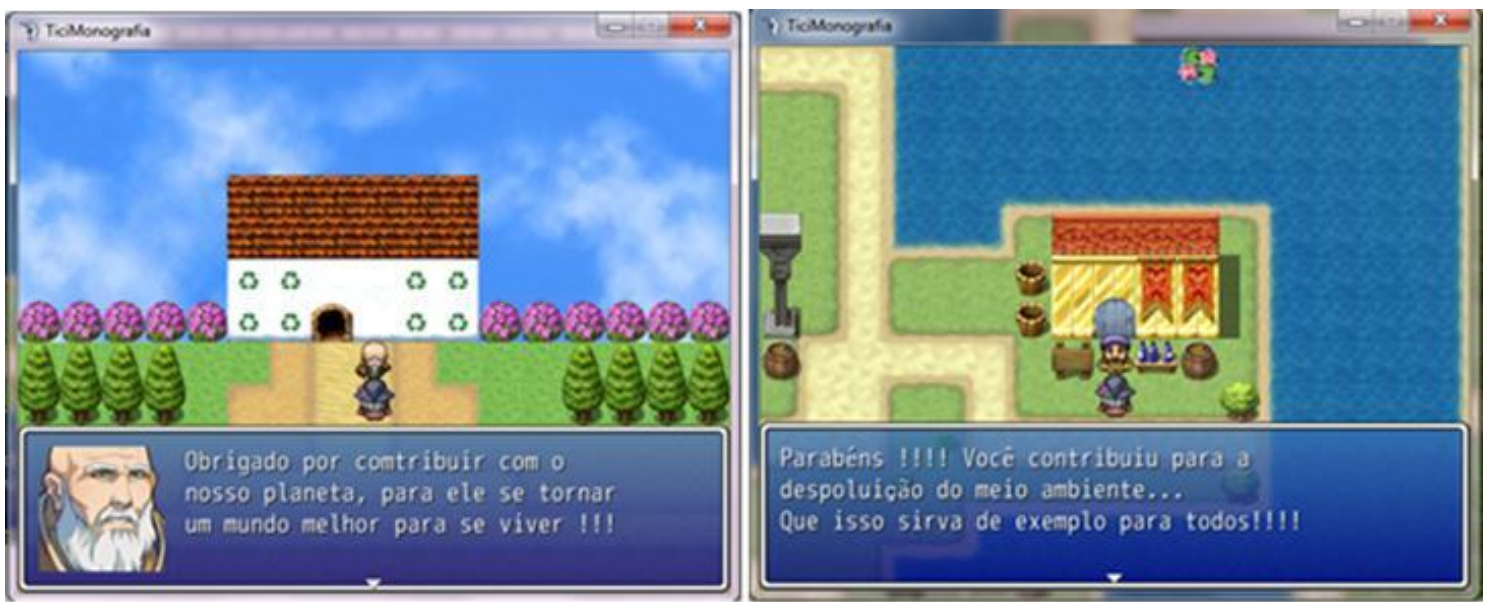

Figura 10: Final do jogo.

Assim, quando o jogo termina sem que o jogador tenha cometido nenhum erro nos problemas dados de maneira contínua, ele consegue finalizar o jogo com o menor nível de poluição da cidade e a vegetação apresenta-se totalmente recuperada e o ar totalmente limpo, no aspecto visual da tela do jogo.

\section{RESULTADOS E DISCUSSÃO}

\subsection{Descrição do software educativo pelos alunos}

Para analisar a viabilidade do jogo RPG Maker, foram apurados os questionários aplicados sob a ótima da análise de conteúdo de Bardin.

Neste questionário buscou-se avaliar o entendimento dos alunos acerca do objetivo do jogo; o que eles acharam do uso de softwares educativos para contribuir no aprendizado, se este instrumento educativo torna as aulas mais interessantes e se eles conseguiram relacionar o conteúdo teórico do jogo com seu cotidiano. Feita a apuração dos resultados dos questionários e a análise e interpretação dos dados, foram obtidos os resultados descritos.

\subsection{Sobre o entendimento do objetivo do jogo}

Os alunos foram indagados sobre o entendimento do objetivo do jogo. Por meio dos resultados apresentados no gráfico da Figura 11, verificou-se que todos os alunos entenderam o objetivo do jogo. Pode-se, então, perceber que os objetivos almejados estavam bastante claros.

Desta maneira, acredita-se que é viável o uso desta ferramenta no processo de ensinoaprendizagem, por auxiliá-lo e ser de fácil compreensão para os alunos. Como esses recursos têm como objetivo incentivar a participação dos alunos, deixando a aula mais dinâmica, eles também podem ser aplicados em outras disciplinas, facilitando a compreensão do assunto abordado na sala de aula. 


\section{Você entendeu o objetivo do jogo?}

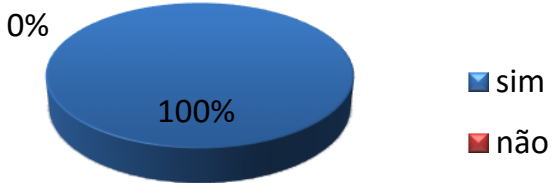

Figura 11: Percentual de alunos que entenderam o objetivo do jogo.

\subsection{Opinião dos alunos sobre o software aplicado ao ensino da Química Ambiental}

A partir das opiniões dos alunos sobre software educativo, pelo gráfico da Figura 12, verificamos que dos 100 alunos pesquisados, $80 \%$ avaliaram o software como excelente e $20 \%$ avaliaram-no como ótimo.

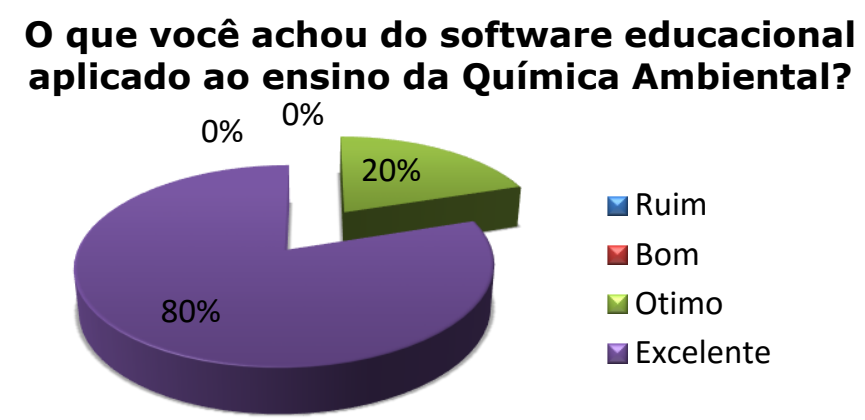

Figura 12: Gráfico, em percentual, relativo à opinião dos educandos sobre o software educacional no ensino de Química Ambiental.

O resultado demonstra que houve uma grande aceitação do software como uma ferramenta educacional, pois nenhum dos alunos considerou-o como ruim ou bom isso indica que eles gostaram muito da utilização do jogo proposto.

Vale salientar que a união dos meios de comunicação e os computadores estão revolucionando a educação e cada vez mais as tecnologias estão permeando as ações pedagógicas.

Uma justificativa para que o programa tenha sido aceito positivamente por parte dos alunos, foi à mudança das atividades em sala de aula, ou seja, as aulas deixaram um pouco de lado sua metodologia tradicional dando espaço a um ensino dinâmico, pois muitas vezes as aulas são passadas para os discentes apenas com conteúdos programáticos o que não possibilita uma aula mais interativa em que o aluno possa construir seu próprio conhecimento. Segundo Freire (2002), ensinar não é transferir conhecimento, mas criar as possibilidades para a sua própria produção ou a sua construção. Portanto, é de fundamental importância criar oportunidades para que o conhecimento seja construído pelos alunos e uma maneira de se conseguir tal fato é trabalhando com aulas divertidas, visto que, além de possibilitarem uma abordagem mais completa dos conteúdos, também despertam neles a motivação para estudar.

Os alunos participaram ativamente do jogo, mostraram grande interesse, desejando inclusive saber como ele foi construído. A todo instante, durante a apresentação do jogo, surgiram perguntas tanto dos alunos como de seus professores. 


\subsection{Opinião dos alunos sobre a contribuição dos jogos para a fixação do conteúdo}

Conforme as respostas obtidas pelos alunos, todos, sem exceção, responderam que o jogo é uma ferramenta que contribui eficazmente para a fixação do conteúdo visto em sala de aula, uma vez que o jogo é uma forma atrativa de rever os conteúdos de uma forma lúdica e prazerosa. Esta observação está representada no gráfico da Figura 13.

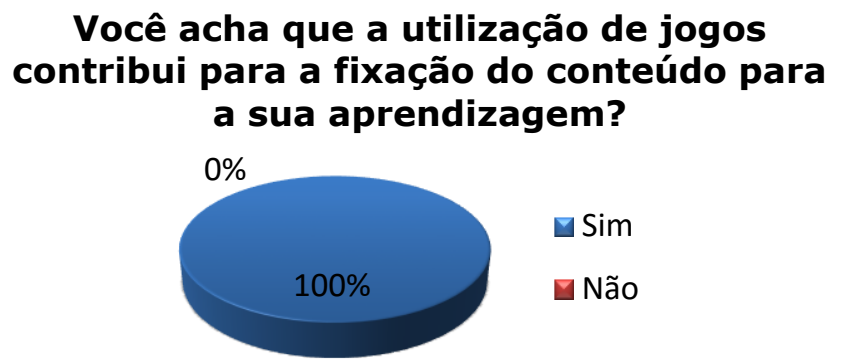

Figura 13: Gráfico, em percentual, relativo à contribuição do jogo para a fixação do conteúdo.

O jogo tem como consequência natural a motivação. É de se esperar que isto aconteça quando esses jogos e atividades forem aplicados ao ensino, além de promover o processo de aprendizagem. Melo (2005) destaca que o jogo é fonte de prazer e de descoberta bem como uma tradução do contexto sócio-cultural-histórico do aluno podendo assim contribuir para processo de construção do conhecimento.

Os jogos são importantes estratégias para o ensino e aprendizagem de conceitos abstratos e complexos, que requerem uma capacidade mais criativa dos alunos para poderem, por exemplo, imaginar a relação entre a Educação Ambiental e o ensino da Química.

Silva, Alves e Santos (2012) elaboram diferentes objetos de aprendizagem a partir de softwares de linguagens simples (RPG Maker ${ }^{\circledR}$, os componentes do Macro Média ${ }^{\circledR}$ - Flash, Dreamweaver, Fireworks - e o Microsoft Office PowerPoint ${ }^{\circledR}$ ) sobre temas relacionados a tabela periódica dos elementos, história da química, funções orgânicas. O que esses autores relataram foi que também obtiveram unanimidade, por parte dos alunos, no fato de que AO melhora a compreensão do conteúdo de química, uma vez que esta disciplina é abstrata.

O RPG eletrônico, assim como o de mesa, pode ser utilizado na educação, pois os jogos eletrônicos em geral apresentam características lúdicas e atrativas, esses jogos têm aparecido como uma possibilidade de facilitar a educação dos jovens, pois é um método de ensino criativo que torna o aprendizado divertido e estimula o aprendizado através de descobertas (Schaffel e Moura, 2011; Ilha e Cruz, 2006).

3.5 Opinião dos alunos sobre a utilização de recursos, como os jogos, para tornar as aulas mais interessantes.

O uso do software educativo deste trabalho teve $100 \%$ de aceitação como um recurso didático para tornar a aula mais interessante, isso se deve ao fato de ser uma forma diferente da tradicional de trabalhar os conteúdos programáticos (Figura 14). Não que esses jogos eliminem totalmente a forma tradicional, mas sim que servem como objetos de aprendizagem que auxiliam o professor e o aluno no processo de ensino e aprendizagem. O jogo é uma ferramenta que 
contribui eficazmente para a fixação do conteúdo visto em sala de aula, uma vez que ele é uma forma atrativa de rever os conteúdos de uma forma lúdica e prazerosa.

Arroio (2006) afirma que a maneira como a química é abordada nas escolas contribui bastante para a falta de interesse de alunos, já que os conceitos são apresentados de forma puramente teórica e, portanto, entediante para a maioria deles.

Com a junção do jogo com a química ambiental, buscou-se criar uma forma alternativa para o ensino de química, através de abordagens práticas, ou seja, a elaboração de um jogo didático para melhorar a percepção e a motivação dos alunos e fazer com que os eles sentissem interesse em estudar.

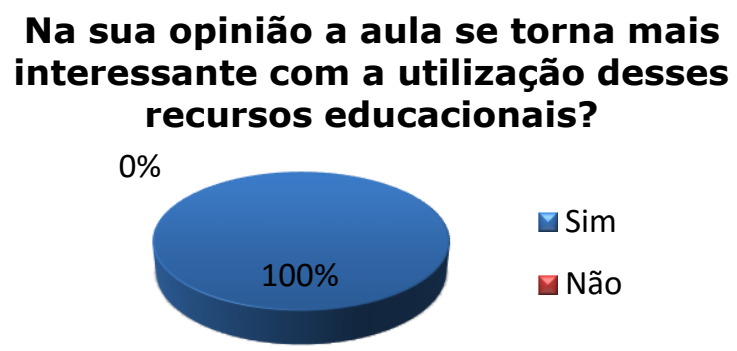

Figura 14: Gráfico, em percentual, relativo a utilização do software para tornar as aulas de Química mais interessante.

É importante destacar que o professor utilize novas metodologias como os softwares educativos como forma de fazer com que o aluno possa participar o mais ativamente possível do processo de ensino-aprendizagem (Haidt, 2003). Porém, vale ressaltar que esse conhecimento de novos métodos de ensino não trará nenhum benefício adicional se o professor continuar a encarar o aluno como um ser passivo e receptivo.

\subsection{Opinião dos alunos sobre a relação do conteúdo teórico do jogo com o seu cotidiano}

Como podemos observar no gráfico da Figura 15, a partir das respostas dos alunos, por unanimidade, todos responderam que conseguiram relacionar o conteúdo teórico do jogo com o seu cotidiano.

A aplicação do software educativo motivou os alunos a participarem, porque além de ser um método inovador e atraente, nele foram abordadas questões vivenciadas pelos alunos no seu dia a dia, como exemplo podemos citar o uso de agrotóxicos na agricultura, que se não forem bem utilizados poderão causar danos ao ser humano. Os alunos fizeram comentários também sobre o perigo do monóxido de carbono que é lançado diariamente pelos escapamentos dos carros nas grandes cidades.

Os jogos didáticos aplicados em sala de aula são capazes de fazer uma ligação entre o conhecimento ensinado e o cotidiano do aluno. Neste contexto, para o ensino de química, foi proposto o jogo como uma ferramenta pedagógica. Para Soares (2008), o jogo é integrador de várias dimensões do aluno, como a afetividade e o trabalho em grupo, promovendo a construção do conhecimento cognitivo, físico e social. 


\section{Você conseguiu relacionar o conteúdo teórico do jogo com o seu cotidiano?}

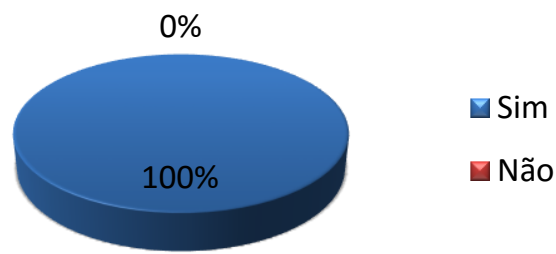

Figura 15: Gráfico, em percentual, relativo a relação do conteúdo teórico do jogo com o cotidiano.

De acordo com os Parâmetros Curriculares Nacionais (BRASIL, 2001):

"[...]um aspecto relevante nos jogos é o desafio genuíno que eles provocam no aluno, que gera interesse e prazer. Desta forma, é importante que os jogos façam parte da cultura escolar, cabendo ao professor analisar e avaliar a potencialidade educativa dos diferentes jogos e o aspecto curricular que se deseja desenvolver" (BRASIL, 2001).

Nesse contexto, acredita-se que o jogo desenvolvido está dentro da cultura escolar e se apresenta como ferramenta de ensino gerador de interesse pela educação ambiental e pela química.

\subsection{Opinião sobre a relação das aulas teóricas com o cotidiano dos alunos}

Ao serem indagados se haveria uma maior facilidade de compreensão e aprendizagem dos conteúdos vistos em sala de aula se estes fossem sempre abordados fazendo relação com o cotidiano, todos os alunos responderam que sim, de acordo com o exposto no gráfico da Figura 16.

Uma justificativa para isto seria que trabalhando paralelamente o conteúdo da sala de aula com o dia a dia do aluno, a aquisição de conhecimento se torna mais efetiva.

A resposta dos estudantes é facilmente justificada, pois como diz Castoldi (2009), uma aula aliada a recursos didático-pedagógicos torna-se mais motivadora e menos cansativa, quando comparada com a aula expositiva tradicional. À medida que essa aula acontece de uma forma diferente e menos cansativa proporciona ao aluno a vontade de aprender.

O RPG também pode ser utilizado como ferramenta avaliativa, através do qual é possível averiguar os conhecimentos dos alunos através da vivência do jogo, discussão e proposição de soluções para determinados problemas, conforme afirmou Nunes, 2004. Dessa maneira, tal recurso possibilita apontar metodologias e estratégias que permitem explorar a explicitação dos conhecimentos dos alunos pelo professor, o que contribui de maneira bastante apropriada ao processo de ensino e aprendizagem.

De igual modo, Cavalcanti e Soares (2009) afirmaram que o RPG pode ser utilizado na intenção de averiguar/avaliar o que o aluno aprendeu nas aulas, como faz uso do conhecimento e se aprendeu corretamente o conhecimento químico. 


\section{Se as aulas teóricas de Química relacionassem sempre o conteúdo visto em sala com o cotidiano, facilitaria mais sua compreensão e aprendizagem?}

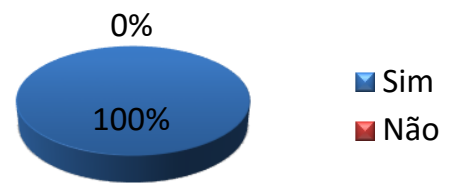

Figura 16: Gráfico, em percentual, relativo à facilitação da compreensão ao relacionar o conteúdo dado com o cotidiano.

\section{CONCLUSÃO}

Este estudo mostrou que a produção do próprio objeto de aprendizagem (OA) torna o trabalho docente mais interessante, pois este irá adaptá-lo à sua realidade e aos seus objetivos conforme mostrou a análise do impacto da aplicação do jogo realizada através de questionário. Na análise feita com os alunos, a partir dos resultados obtidos a partir do questionário avaliativo do jogo, pôde-se perceber que este recurso apresentou ser uma excelente ferramenta no processo de ensino e aprendizagem de uma maneira geral, pois segundo os alunos a aula se torna mais dinâmica, interessante, contextualizada, contribuindo para a melhoria da aprendizagem. De tal forma que o ensino de química e a educação ambiental são trabalhados de forma contínua, ou seja, não fragmentados, contribuindo para formação de um cidadão crítico e consciente de seu papel na sociedade em que está inserido. Conforme afirmaram Oliveira, Pierson e Zuin (2009), através do jogo de RPG, foram observados indícios de uma postura reflexiva por parte dos alunos frente ao problema ambiental, bem como o reconhecimento da interface com a questão econômica, científica, tecnológica e social.

\section{REFERÊNCIAS}

1. ARROIO, A.; HONÓRIO, K. M.; WEBER, K. C.; HOMEM-DE-MELO, P.; GAMBARDELLA, M. T. P. e SILVA, A. B. F. O show da Química: motivando o interesse científico. Química Nova, v. 29, n. 1, p. 173-178, 2006. Em: http://www.scielo.br/pdf/qn/v29n1/27876.pdf

2. BRASIL. Lei no 9.795, de 27 de abril de 1999. Presidência da República, Casa Civil, Subchefia para Assuntos Jurídicos, Brasília, DF, 27 abril. 1999. Em: http://www.planalto.gov .br/ccivil_03/leis/I9795.htm

3. BRASIL. Parâmetros Curriculares Nacionais: Matemática. 3 ed. Brasília: MEC/SEF, 2001.

4. BITTENCOURT, J. R. e GIRAFFA, L. M. M. A utilização dos Role-Playing Games Digitais do processo de ensino-aprendizagem. Pontifícia Universidade do Rio Grande do Sul (PUCRS), Faculdade de Informática. Programa de Pós-Graduação e Ciência da Computação, 2003.. Em: http://www3.pucrs.br/pucrs/files/uni/poa/facin/pos/relatoriostec/tr031.pdf

5. CASTOLDI, R.; POLINARSKI, C. A. A Utilização de Recursos Didático-Pedagógicos na Motivação da Aprendizagem. Anais do II Simpósio Nacional de Ensino de Ciência e Tecnologia, 2009.

6. CARVALHO, I. A Invenção ecológica. Porto Alegre: UFRGS, 2001.

7. CAVALCANTI, E. L. D., SOARES, M. H. F. B. O uso do jogo de roles (roleplaying game) como 
estratégia de discussão e avaliação do conhecimento químico. Revista Electrónica de Enseñanza de las Ciencias, v. 8, n. 1, p. 255-282, 2009. Em: http://reec.uvigo .es/volumenes/volumen8/ART14_Vol8_N1.pdf

8. FERREIRA, E. Educação ambiental e desenvolvimento de práticas pedagógicas sob um novo olhar da ciência química. Americana: Centro Universitário Salesiano de São Paulo, 2010.

9. FREIRE, P. Pedagogia da Autonomia: saberes necessários à prática educativa. São Paulo: Terra e Paz, 2002.

10. GOMES, A. S.; PADOVANI, S. Usabilidade no ciclo de desenvolvimento de software educativo. Simpósio Brasileiro de Informática na Educação, 2005. Em: http://www.cin.ufpe .br/ asg/publications/files/gomes_padovani_mini_curso_sbie_2005.pdf

11. GUTIERREZ, S. S. Distribuição de conteúdos e aprendizagem on-line. Revista Novas Tecnologias na Educação, v.2, p. 1-14, 2004.

12. HAIDT, R. C. C. Curso de Didática Geral. São Paulo: Ática, 2003.

13. ILHA, P. C. A e CRUZ, D. M. Jogos eletrônicos na educação: uma pesquisa aplicada do uso do Sim City4 no ensino médio. XII Workshop de Informática na Escola. Campo Grande/MS, 2006. Em: http://www.academia.edu/2285194/Jogos_eletronicos_na_educacao_uma_pesquisa_a plicada_do_uso_do_Sim_City4_no_ensino_medio

14. MELO, C. M. R. As atividades lúdicas são fundamentais para subsidiar ao processo de construção do conhecimento (continuação). Información Filosófica, v. 2, n. 1, p. 128-137, 2005.

15. NASCIMENTO JR., F. A.; PIETROCOLA, M. O papel do RPG no ensino de física. Atas do V Encontro nacional de pesquisa em educação em ciências. Bauru: ABRAPEC, 2005. Em: http://www.nutes.ufrj.br/abrapec/venpec/conteudo/artigos/3/pdf/p565.pdf

16. NUNES, H. F. O jogo RPG e a socialização do conhecimento. Revista Eletrônica de Biblioteconomia e Ciência da Informação, n. esp., p. 75-85, 2004.

17. OLIVEIRA, R. C.; PIERSON, A. H. e ZUIN, V. G. O uso do Role Playing Game (RPG) como estratégia de avaliação da aprendizagem no Ensino de Química. VII Encontro Nacional de Pesquisas em Educação em Ciências, 2009. Em: http://posgrad.fae.ufmg.br/posgrad/vii enpec/pdfs/961.pdf

18. SOARES, M. Jogos para o Ensino de Química: Teoria, Método e Aplicações. Guarapari: ExLibris, 2008.

19. SCHAFFEL, V. O. S. e MOURA, R. M. Utilização do roleplayng game (RPG) eletrônico como ferramenta metodológica de aprendizagem em biologia, $V$ Colóquio Internacional Educação e Contemporaneidade, São Cristovão - SE/Brasil, 2011. Em: http://www.educonufs.com.br/v coloquio/cdcoloquio/cdroom/eixo\%208/PDF/Microsoft\%20Word\%20-\%20UTILIZAcaO\%20D O\%20ROLEPLAYNG\%20GAME_RPG_ELETRONICO\%20COMO\%20FERRAMENTA\%20METODOL OGICA\%20DE\%20APRENDIZAGEM\%20EM\%20BIOLOGIA.pdf

20. SILVA, L. O. P.; ALVES, B. H. P. e SANTOS, V. F. Objetos de Aprendizagem: o aquilato de professores e alunos do ensino médio e a criação de alguns $O A$ usando softwares de linguagens simples. XVI Encontro Nacional de Ensino de Química (XVI ENEQ) e X Encontro de Educação Química da Bahia (X EDUQUI), 2012. Em: http://www.portalseer.ufba.br/index .php/anaiseneq2012/article/view/7980/5869 